\title{
FABRICAÇÃO DE FILMES BIONANOCOMPÓSITOS À BASE DE PECTINA E POLPA DE CACAU COM POTENCIAL USO COMO EMBALAGEM PARA ALIMENTOS
}

\author{
Pamela Thais S. Melo, Fauze A. Aouada* e Marcia R. de Moura
}

Departamento de Física e Química, Faculdade de Engenharia de Ilha Solteira, Universidade Estadual Paulista, $15385-000$ Ilha Solteira - SP, Brasil

Recebido em 11/04/2016; aceito em 20/10/2016; publicado na web em 21/11/2016

\begin{abstract}
PRODUCTION OF NANOCOMPOSITE FILMS OF PECTIN BASED ON COCOA PUREE WITH POTENTIAL USE AS PACKAGING FOR FOOD. The aim of this work was to produce biodegradable films based on the pectin and cocoa puree reinforced with chitosan nanoparticles. Nanoparticles were obtained by the ionotropic gelation. Films were produced according to the "casting" method, through a colloidal solution composed of water, cocoa puree, chitosan nanoparticles solution and different concentrations of pectin $(2 \%$ and $3 \% \mathrm{w} / \mathrm{w})$. Films were analyzed by thickness measurements, water vapor permeability, mechanical properties and scanning electron microscopy. Nanoparticles were characterized by zeta potential and showed spherical shape with a diameter of about $110 \mathrm{~nm}$ and zeta potential value of approximately $+30 \mathrm{mV}$. Pectin $2 \%$ and $3 \%$ cocoa films exhibited tensile strength (mPa) of $15.1 \pm 0.7$ and $22.9 \pm 1.6$, respectively. After nanostructures addition, values increased to $25.2 \pm 0.7$ and $29.8 \pm 1.3$. Increasing concentration polymer and chitosan nanoparticles to improve tensile strength values. Films contained $3 \%$ of pectin exhibited more significant decrease in water vapor permeability values when chitosan nanoparticles were added, from $2.470 \pm 0.101$ to $1.904 \pm 0.125$ $\mathrm{g} \mathrm{mm} / \mathrm{kPa} \mathrm{h} \mathrm{m}{ }^{2}$. Results of the analyzes demonstrated that nanocomposites produced with pectin of different concentration showed satisfactory properties for application as packaging for food.
\end{abstract}

Keywords: edible films; chitosan nanoparticles; pectin.

\section{INTRODUÇÃO}

Os resíduos gerados pelo descarte de embalagens produzidas por fontes não renováveis vêm crescendo a cada ano e constituem um grande problema do ponto de vista ambiental. Boa parte destes resíduos provém das embalagens usadas em produtos alimentícios, impulsionando pesquisas com foco no desenvolvimento de filmes comestíveis biodegradáveis obtidos através de biopolímeros. ${ }^{1,2}$

Atualmente, o mercado global vem buscando oferecer produtos e alimentos mais naturais, com mais qualidade e segurança, por conta da demanda crescente dos consumidores, que estão cada vez mais exigentes e mais preocupados com a qualidade de vida, saúde e bem-estar. Para atender às necessidades do mercado, estão sendo desenvolvidas as chamadas "embalagens ativas", que são aquelas que, além de servirem como barreira entre o meio externo e interno, exercem uma outra função na preservação do alimento. ${ }^{3}$

Filmes comestíveis podem ser uma alternativa para estender a vida de prateleira dos alimentos, servindo como barreira à passagem de gases e podendo também carrear substâncias capazes de retardar a contaminação por micro-organismos. ${ }^{4,5}$

Os biopolímeros mais utilizados na formação dos filmes comestíveis são as proteínas, os polissacarídeos e os lipídeos. Dentre as proteínas, merecem destaque a gelatina, caseína, ovoalbumina, glúten de trigo, zeína e proteínas miofibrilares. Os polissacarídeos que se destacam são o amido, a quitosana, a pectina e a celulose. Já os lipídios, pode-se destacar o uso dos monoglicerídeos acetilados, ácido esteárico, ceras e ésteres de ácido graxo. ${ }^{6}$

Além do componente principal para a formação da matriz polimérica, as soluções filmogênicas são constituídas de solvente (água, etanol, solução de ácido acético, etc.) e podem ser incorporados diversos aditivos, tais como: plastificantes, agentes reticulantes, agentes antimicrobianos, agentes reguladores de $\mathrm{pH}$, etc. ${ }^{7}$

*e-mail: faouada@yahoo.com.br
Entretanto, embalagens à base de polímeros naturais apresentam algumas propriedades físico-químicas desfavoráveis, por exemplo, baixas propriedades de barreira e baixa resistência mecânica quando comparadas às embalagens tradicionais, dificultando, assim, a sua utilização. ${ }^{8}$ Por este motivo, pesquisadores têm buscado a inserção de materiais nanoestruturados às matrizes biopoliméricas no intuito de melhorar suas propriedades. Uma das formas reportadas na literatura inclui a adição de nanopartículas (NPs) de quitosana (QS) às matrizes formadoras dos filmes. ${ }^{9}$

Moura et al. ${ }^{10}$ verificaram que o uso de NPs de QS, obtidas pelo método de gelatinização ionotrópica, melhoram as propriedades térmicas e mecânicas e diminuem a permeabilidade ao vapor de água (WVP) de filmes de hidroxipropilmetilcelulose (HPMC) quando comparados àqueles obtidos apenas com HPMC. Hosseini et al. ${ }^{11}$ também relataram aumento do módulo elástico e da deformação até o ponto de ruptura de filmes contendo gelatina de peixe e NPs de QS.

O presente trabalho propõe a síntese de nanopartículas de quitosana para serem incorporadas aos filmes contendo pectina e polpa de cacau. A adição das nanoestruturas tem como objetivo melhorar as propriedades mecânicas e a permeabilidade ao vapor de água dos filmes. O cacau (Theobroma cacao L.) possui alto valor nutricional, principalmente devido à presença de flavonoides em sua composição, possuindo atividade antioxidante, anti-inflamatória, antimicrobiana e anticarcinogênica, o que motivou a escolha deste fruto para compor a matriz polimérica. ${ }^{12,13}$

Trabalhos têm relatado o uso de polpas de frutas como principais componentes no preparo de soluções poliméricas para a formação de filmes comestíveis com o intuito de adicionar propriedades nutricionais, flavorizantes e conservantes. ${ }^{14}$ Martelli et al. ${ }^{15}$ relataram melhora nas propriedades mecânicas e de permeabilidade ao vapor de água em filmes contendo purê de banana. Lorevice et al. ${ }^{16}$ desenvolveram filmes comestíveis nanoestruturados com purê de goiaba, relatando melhora nas propriedades mecânicas e térmicas. Azeredo et al. ${ }^{17}$ adicionaram purê de manga à matriz polimérica, não só devido ao seu 
alto teor de polissacarídeo, mas também por agregar características desejáveis ao filme, como cor e sabor.

\section{PARTE EXPERIMENTAL}

\section{Material}

Polpa de cacau obtida da DE MARCHI. Pectina (Grau de metoxilação > 50\%) obtida da CP Kelco (Limeira, Brasil). Quitosana (Grau de desacetilação =94\%) comercializada pela Polymar Ciência e Nutrição S/A (Fortaleza, Brasil). Tripolifosfato de sódio (TPP) e ácido acético obtidos da Sigma-Aldrich Chemical Co. (St. Louis, MO).

\section{Síntese das nanopartículas}

As nanopartículas de quitosana foram sintetizadas pelo método de gelatinização ionotrópica, descrito primeiramente por Calvo et al. ${ }^{13}$ Inicialmente solubilizou-se a quitosana em uma solução de ácido acético a fim de se obter uma concentração de $3 \%(\mathrm{~m} / \mathrm{v})$. Posteriormente, a esta solução foi adicionada uma solução contendo $0,6 \%(\mathrm{~m} / \mathrm{v})$ de tripolifosfato de sódio (TPP), mediante agitação contínua e taxa de adição controlada (1 mL/min). A zona de suspensão opalescente que surgiu após a adição do TPP foi atribuída à formação das nanoestruturas.

\section{Tamanho médio e potencial zeta das nanopartículas}

A carga superficial e o tamanho médio das nanopartículas foram determinados no aparelho Zetasizer Nano Series (Malvern Instruments Ltd. Malvern, Worcestershire, UK), utilizando o princípio da difração do raio laser. As medidas para cada amostra foram realizadas em triplicata, a $25^{\circ} \mathrm{C}$.

\section{Preparo dos filmes comestíveis}

Os filmes foram produzidos por "casting", através do preparo de uma solução coloidal contendo $50 \mathrm{~g}$ de água, $48 \mathrm{~g}$ de polpa de cacau integral industrializada com cerca de $10 \mathrm{~g}$ de sólidos e $2 \mathrm{~g}$ ou $3 \mathrm{~g}$ de pectina (filmes sem nanoestruturas) e outra contendo $50 \mathrm{~g}$ de solução de NPs de QS, $48 \mathrm{~g}$ de polpa de cacau e $2 \mathrm{~g}$ ou $3 \mathrm{~g}$ de pectina (filmes nanoestruturados). Em seguida, $50 \mathrm{~g}$ de cada solução filmogênica foi espalhada em suporte retangular de aproximadamente $15 \mathrm{~cm}$ x 20 $\mathrm{cm}$ com auxílio de uma barra de nível para controle da espessura e secadas à temperatura ambiente $\left(27^{\circ} \mathrm{C} \mathrm{a} 30^{\circ} \mathrm{C}\right)$ por $48 \mathrm{~h}$.

\section{Determinação da espessura}

As medidas das espessuras dos filmes foram realizadas utilizando um micrômetro digital (No. 7326, Mitutoyo Manufacturing, Japan) em 5 diferentes pontos ao redor do filme. Os valores obtidos foram utilizados para calcular a permeabilidade de vapor de água e propriedades mecânicas.

\section{Permeabilidade ao vapor de água}

Para determinação da permeabilidade ao vapor de água (WVP) dos filmes utilizou-se o método modificado ASTM E96-80, ${ }^{18}$ descrito na literatura por McHugh et al. ${ }^{19}$

As amostras foram cortadas em formato circular com diâmetro de $15,5 \mathrm{~cm}$ e fixadas em células padronizadas de Teflon ${ }^{\circledR}$ contendo 6 $\mathrm{mL}$ de água destilada. Em seguida, foram armazenadas em estufa a $25{ }^{\circ} \mathrm{C}$ contendo sílica gel para controle de umidade e temperatura. A quantidade de água transferida pelos filmes foi determinada através de pesagens periódicas das células (pesagem inicial, após 1 h, 2 h, 23 h, 24 h e 25 h). Os valores das massas das células foram utilizados para calcular a umidade relativa $(\mathrm{RH})$, velocidade de transmissão ao vapor de água (WVTR) e WVP. As análises foram feitas em triplicata.

\section{Propriedades mecânicas}

O teste mais utilizado para a determinação da resistência mecânica de filmes é o teste de tensão x deformação sob tração. As propriedades mecânicas dos filmes foram determinadas pelos testes de tração. Os filmes foram acondicionados em ambiente com $30 \%$ de umidade relativa a $24{ }^{\circ} \mathrm{C}$ por $24 \mathrm{~h}$ antes dos testes. Os filmes foram cortados em forma retangular nas dimensões de acordo com o método ASTM D882-9720 (15 mm de largura e $100 \mathrm{~mm}$ de comprimento). O equipamento utilizado para a análise foi um Instron Universal Testing Machine (Modelo 3369, Instron Corp., Canton, Mass., U.S.A.). A velocidade de tracionamento utilizada foi de $50 \mathrm{~mm} / \mathrm{min}$. Para cada tipo de filme foram realizados pelo menos 5 ensaios.

A deformação $(\varepsilon)$ dos filmes foi determinada pela equação abaixo:

$$
\varepsilon=\ln \left(\frac{L}{L_{0}}\right) \times 100
$$

em que $\mathrm{L}_{\text {e }} \mathrm{L}_{0}$ são os comprimentos de elongação do filme durante o experimento e o comprimento inicial do filme, respectivamente.

A tensão $(\sigma)$ foi determinada medindo-se a força necessária para romper o filme. Os valores de $\sigma$ foram obtidos utilizando a seguinte equação:

$$
\sigma=\frac{F}{S}
$$

Fé o valor da força de ruptura exercida e $\mathrm{S}$ é a área seccional do filme. O módulo de elasticidade (E) foi calculado a partir da inclinação inicial da curva obtida tensão-deformação ( $\sigma$ vs $\varepsilon$ ).

\section{Microscopia eletrônica de varredura}

Os filmes foram analisados utilizando um microscópio eletrônico de varredura (MEV), da marca Zeiss, modelo EVO LS15, da UNESP campus de Ilha Solteira, operando com voltagem de $5,00 \mathrm{kV}$ a 10,00 kV. Sobre as amostras foi depositada uma fina camada de ouro usando um Sputter Coater.

\section{Análise estatística}

Os dados foram analisados usando o software estatístico Minitab 14.12.0 por análise de variância do tipo one-way (ANOVA) através de teste de comparação de Tukey com nível de confiança de $95 \%$.

\section{RESULTADOS E DISCUSSÃO}

A solução de NPs apresentou-se opalescente após a síntese, o que é um indício da formação das mesmas. Apresentaram tamanho médio em torno de $110 \pm 4 \mathrm{~nm}$. O tamanho das NPs está relacionado às concentrações de quitosana e TPP, como já descrito por Calvo em 1997.13

As soluções apresentaram potencial zeta de aproximadamente + $30 \mathrm{mV}$. A estabilidade de uma solução coloidal de NPs de QS pode ser determinada através dos valores de potencial zeta. Segundo Lorevice et al. ${ }^{21}$ o potencial zeta depende do tamanho de partícula, pois quanto maior o tamanho da partícula, maior será a concentração de íons $\mathrm{NH}_{3}{ }^{+}$. O valor de potencial zeta obtido é favorável para formação de suspensões de partículas estáveis, uma vez que são superiores, em módulo, a + $20 \mathrm{mV}^{21,10}$ 
Os filmes foram analisados subjetivamente levando em consideração três aspectos: continuidade (ausência de rupturas e fraturas depois de secos), homogeneidade (ausência de partículas insolúveis a olho nu, áreas com textura ou cores diferentes) e manuseabilidade (capacidade de manipulação dos filmes e retirada dos moldes de secagem sem que houvesse rupturas). Os filmes contendo apenas polpa de fruta não apresentaram as características mencionadas acima, sendo necessária a adição de pectina para a formação dos mesmos. Os demais se formaram satisfatoriamente e a presença ou não de NPs, bem como a variação da concentração do polímero, também não influenciaram tais propriedades.

Os filmes contendo polpa de cacau apresentaram características sensoriais desejáveis, como cor e odor característicos da polpa utilizada e mesmo depois de certo tempo de estocagem (em torno de 6 meses), estas propriedades se mantiveram. A Figura 1 se refere ao filme contendo polpa de cacau e nanopartículas de quitosana.

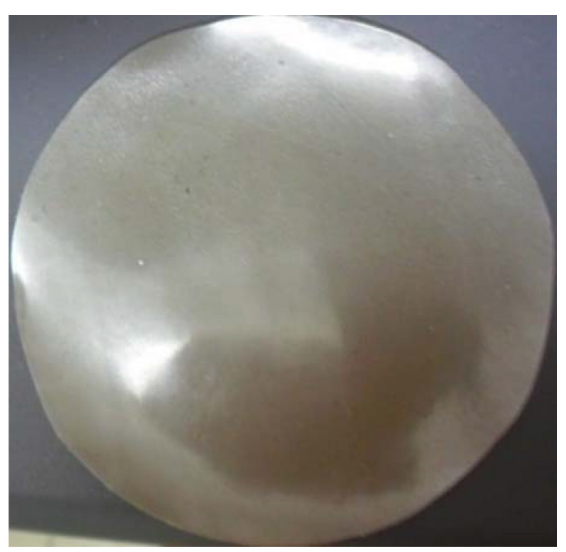

Figura 1. Fotografia digital do filme bionanocompósito contendo pectina, polpa e nanopartículas

A espessura média dos filmes foi maior para aqueles contendo maior concentração do polímero e para os que continham polpa de cacau, conforme a Tabela 1. A espessura pode ser influenciada pela quantidade e tipo de componentes da matriz polimérica, técnica de preparo, tipo de solvente utilizado, dentre outros fatores.

A adição de nanoestruturas teve como objetivo melhorar as propriedades físico-químicas. De acordo com a Tabela 1, pode-se observar que com a adição de polpa de cacau e com o aumento da concentração de pectina houve um acréscimo nos valores das espessuras dos filmes. A adição de NPs causou uma diminuição na espessura dos filmes devido às interações entre as cadeias poliméricas e as nanoestruturas, o que favorece uma maior compactação da matriz. A adição de polpa influenciou significativamente para o aumento da espessura causado pelo teor de sólidos presente na polpa. Além disso, com o aumento da concentração de pectina ocorre uma diminuição da permeabilidade, sendo os menores valores para os filmes contendo apenas o polímero. Com a adição da polpa estes valores aumentam. De acordo com Lorevice et al.,${ }^{21}$ existe uma diferença entre as quantidades de moléculas entre os filmes e que parte da água fica retida na matriz atuando como um plastificante, sendo atribuído este aumento de permeabilidade à diferença entre a quantidade de moléculas que se difundem no material e aquelas que se desprendem do mesmo.

Quando se adicionam as NPs ocorre uma diminuição da permeabilidade ao vapor de água dos filmes quando comparados àquele contendo apenas pectina e polpa de cacau. Isto se deve ao fato de que as nanoestruturas preenchem os poros das matrizes. Em 2010, segundo Chang et al., ${ }^{22}$ a adição de NPs de QS dificulta a passagem de moléculas de água pela matriz do filme por preencher os espaços das cadeias poliméricas.

Moura et al. ${ }^{10}$ constataram diminuição nos valores de WVP de filmes de HPMC nanoestrutrados devido às ligações de hidrogênio existentes entre as nanopartículas e o polímero. Dados semelhantes foram encontrados por Lorevice et al. ${ }^{16} \mathrm{em}$ um estudo das propriedades de filmes de polpa de goiaba e NPs de QS sintetizadas por polimerização em molde de ácido metacrílico. Lorevice et al. ${ }^{21}$ também verificaram que filmes de HPMC e polpa de mamão apresentaram decréscimo nos valores de WVP na presença de NPs de QS.

De acordo com os resultados descritos nas Figuras 2 e 3, foi possível observar que com o aumento da concentração do polímero e adição de NPs de QS, houve um acréscimo nos valores de tensão $(\sigma)$ e um decréscimo na \% de elongação dos filmes. As NPs interagem com a matriz diminuindo o escoamento entre as cadeias, dificultando o rompimento do filme. De acordo com Martelli et al. ${ }^{15}$ os açúcares presentes na polpa atuam como plastificante, entretanto, com a adição de NPs esse efeito plastificante diminui. Os plastificantes reduzem as forças intermoleculares entre as cadeias poliméricas, melhorando a flexibilidade, força e resistência dos filmes. ${ }^{23}$ Uma diminuição na elongação também foi observada por Gómez-Estaca et al..$^{24} \mathrm{em}$ filmes de gelatina de peixe e quitosana. As nanoestruturas diminuem o volume livre entre as cadeias do polímero, aumentando as forças intermoleculares ma matriz. ${ }^{11}$

De acordo com Moura et al. ${ }^{10}$ a incorporação de nanoestruturas nos filmes pode aumentar a resistência mecânica devido à substituição parcial do polímero por nanoestruturas na matriz do nanocompósito. Outro motivo pode ser a ocupação de parte dos espaços vazios entre as cadeias do polímero pelas nanoestruturas, o que causa um aumento na resistência decorrente de uma maior compactação da matriz.

Ainda na Figura 3 podemos observar que ocorre uma melhoria na elongação dos filmes com polpa de fruta. Mesmo com a adição de nanopartículas esses filmes ainda permanecem com uma elongação maior que os filmes contendo apenas pectina. Essa característica é interessante uma vez que as utilizações de filmes com maior tenacidade na área de embalagens são muito requisitadas. Apesar de essa tenacidade diminuir com a adição de nanopartículas, ela ainda está melhor que a dos filmes contendo somente pectina. Esse resultado é bastante inovador nessa área, uma vez que não são encontrados

Tabela 1. Espessura média dos filmes e valores de permeabilidade ao vapor de água

\begin{tabular}{lcc}
\hline Tipos de filmes & Espessura $(\mathrm{mm})$ & $\mathrm{WVP}\left(\mathrm{g} \mathrm{mm} / \mathrm{kPa} \mathrm{h} \mathrm{m}^{2}\right)$ \\
\hline Pectina 2\% & $0,022 \pm 0,008$ & $0,415 \pm 0,011^{\mathrm{a}}$ \\
Pectina 2\% + polpa & $0,143 \pm 0,009$ & $2,696 \pm 0,028^{\mathrm{c}}$ \\
Pectina 2\% + polpa + NPs & $0,123 \pm 0,013$ & $2,467 \pm 0,114^{\mathrm{c}}$ \\
Pectina 3\% & $0,029 \pm 0,010$ & $0,333 \pm 0,030^{\mathrm{a}}$ \\
Pectina 3\% + polpa & $0,177 \pm 0,008$ & $2,470 \pm 0,101^{\mathrm{c}}$ \\
Pectina 3\% + polpa + NPs & $0,139 \pm 0,016$ & $1,904 \pm 0,125^{\mathrm{b}}$ \\
\hline
\end{tabular}

${ }_{\mathrm{a}, \mathrm{b}, \mathrm{c}}$ Diferentes letras dentro nas colunas indicam diferença significativa a $\mathrm{P}<0,05$. 


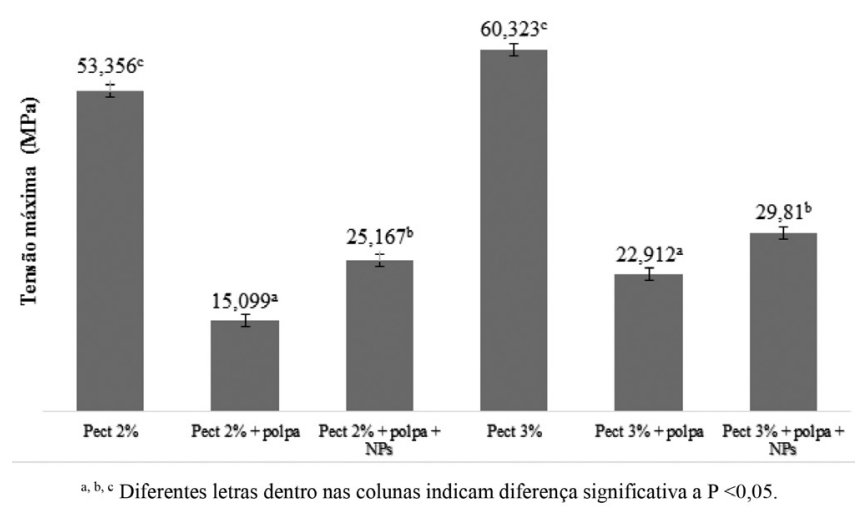

Figura 2. Diferentes valores de tensão máxima de ruptura dos filmes

ainda na literatura relatos do comportamento de filmes de polpa de cacau melhorados com nanopartículas de quitosana que apresentem tenacidade satisfatória.

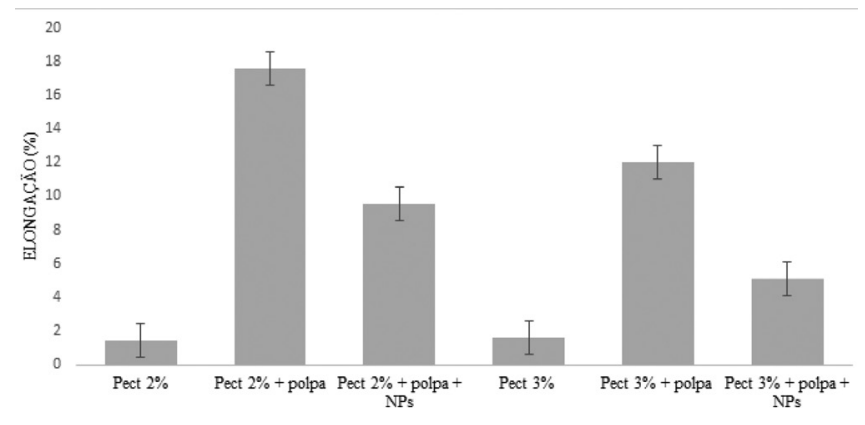

Figura 3. Diferentes valores de elongação dos filmes

Nas Figuras 4 e 5 é possível observar através das análises de MEV os efeitos da adição de polpa de cacau na microestrutura dos filmes. O filme contendo polpa apresenta-se mais heterogêneo devido à presença dos açúcares na polpa. Em um trabalho com filmes de pectina e polpa de açaí, resultados semelhantes foram relatados. Os filmes contendo somente pectina apresentaram uma superfície mais homogênea quando comparados aos filmes que continham açaí. ${ }^{14}$

Nas Figuras 6 e 7 são apresentadas as imagens de microscopia eletrônica de varredura (MEV) da fratura dos filmes sem nanoestruturas e filmes nanoestrutrados, respectivamente. As nanopartículas

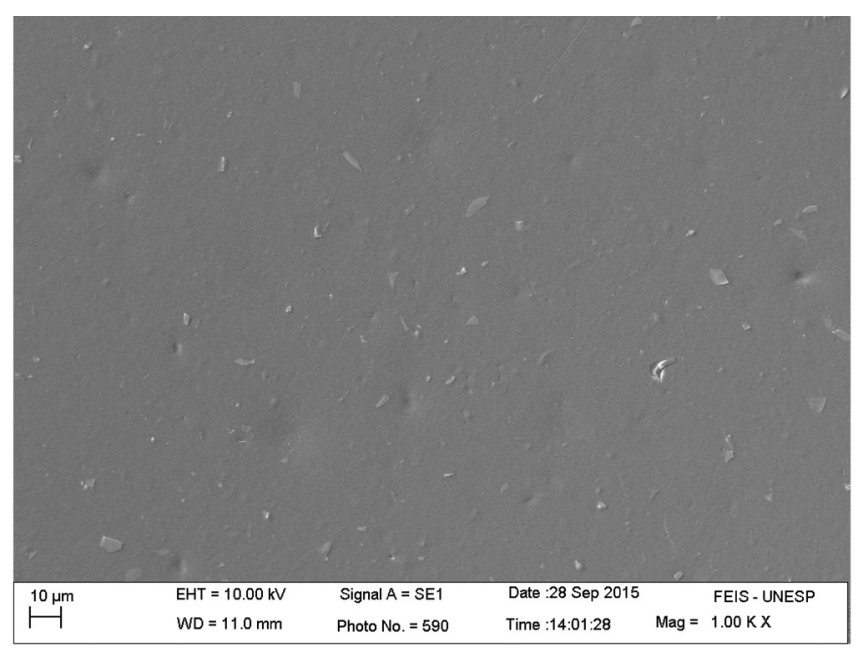

Figura 4. Micrografia obtida por MEV da superfície do filme de pectina. A micrografia possui magnitude de $1000 \mathrm{X}$

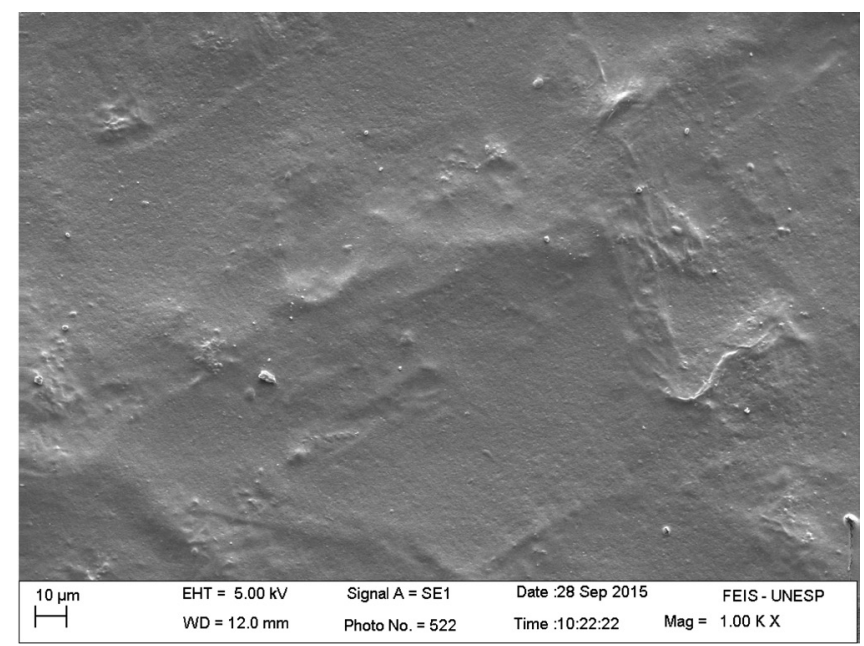

Figura 5. Micrografia obtida por MEV da superfície do filme de pectina e polpa de cacau. A micrografia possui magnitude de $1000 \mathrm{X}$

passam a ocupar os poros dos filmes aumentando sua compactação, funcionando como um mecanismo de reforço. Lorevice et al. ${ }^{21}$ também relataram diminuição na quantidade de poros em filmes de

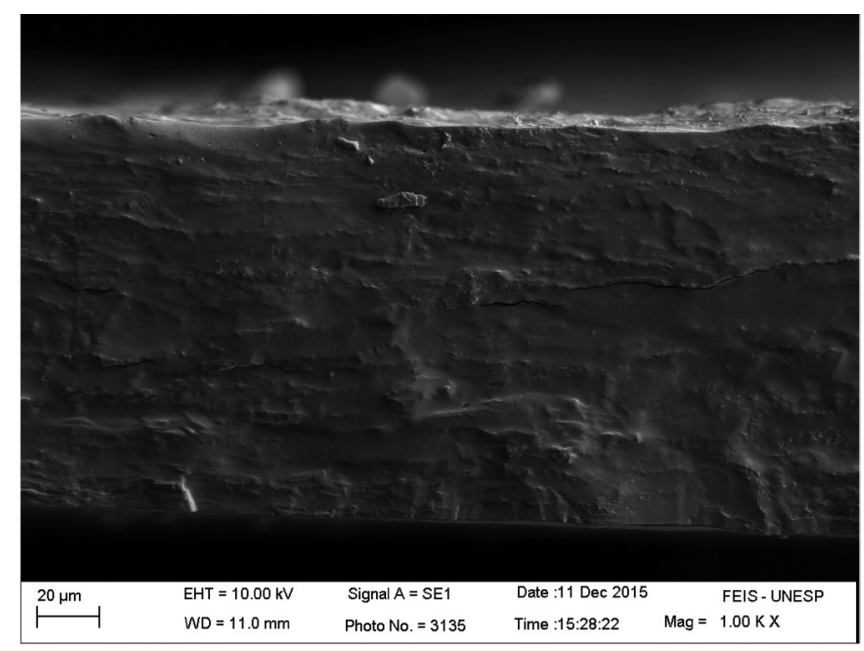

Figura 6. Micrografia de fratura obtida por MEV do filme de pectina e polpa de cacau. A micrografia possui magnitude de $1000 \mathrm{X}$

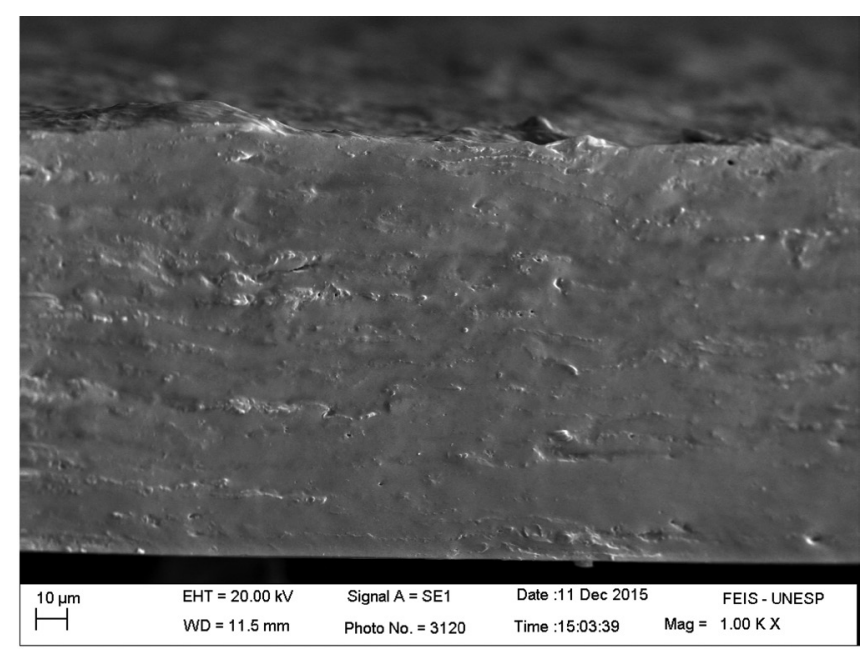

Figura 7. Micrografia de fratura obtida por MEV do filme de polpa de cacau e pectina contendo nanopartículas. A micrografia possui magnitude de $1000 \mathrm{X}$ 
HPMC e polpa de mamão quando a estes foram adicionadas nanopartículas de quitosana. Além disso, pode-se observar que a adição das NPs causou uma modificação na microestrutura do filme, tornando a matriz mais heterogênea. Resultados semelhantes foram reportados por Hosseini et al. ${ }^{11} \mathrm{e}$ Huq et al. ${ }^{25} \mathrm{em}$ matrizes de alginato e celulose microcristalina.

Se observarmos a Figura 7 podemos notar as nanopartículas espalhadas na matriz do filme. Como foi dito anteriormente, essas partículas funcionam como agentes de reforço, além de diminuírem a interação da matriz com a água, tornando o filme mais hidrofóbico. Essa característica é de primordial importância nessa área, pois com a adição de polpa de fruta, filmes comestíveis se tornam muito hidrofílicos, prejudicando algumas aplicações. Essa dispersão uniforme de nanopartículas que visualizamos na matriz a torna mais hidrofóbica, ampliando a área de aplicação dessas. Resultados desse tipo são de grande importância quando se pensa na aplicação que será dada ao material, pois não precisamos descartar uma aplicação da embalagem contendo polpa de cacau pelo simples fato dela possuir baixa barreira a vapores de água. Podemos aproveitar todos os benefícios que uma embalagem desse tipo oferece, como propriedades nutritivas, antioxidantes, além de sabor e aroma agradáveis.

\section{CONCLUSÕES}

As nanopartículas foram sintetizadas com sucesso, resultando em partículas em escala nanométrica. Foram obtidos filmes bionanocompósitos com propriedades satisfatórias. O presente estudo sugere que os filmes bioativos nanoestruturados oferecem grande potencial para serem aplicados como embalagens de alimentos. Foram observadas diminuição da permeabilidade ao vapor de água nos filmes contendo nanopartículas de quitosana, conforme esperado. A adição de polpa de cacau nas matrizes poliméricas, além de acrescentar propriedades sensoriais nos filmes, melhorou a elasticidade destes. De acordo com resultados obtidos pelas análises de microscopia eletrônica de varredura, foi possível observar que as nanopartículas encontraram-se dispersas de forma homogênea na matriz polimérica e que esta tornou-se mais compacta e resistente, como mostraram também os ensaios mecânicos. Sendo assim, a nanotecnologia pode servir de grande auxílio para melhorar as propriedades dos filmes, contribuindo para o desenvolvimento de novos materiais.

\section{AGRADECIMENTOS}

Os autores agradecem à UNESP, EMBRAPA, CAPES, FAPESP e ao CNPq.

\section{REFERÊNCIAS}

1. Sun, X.; Minowa, T.; Yamaguchi, K.; Genchi, Y.; J. Cleaner Prod. 2015, 87, 208.

2. Razavi, S. M. A.; Amini A. M.; Zahedi, Y.; Food Hydrocolloids 2015, 43, 290.
3. Rooney, M. In Proceedings of the First Japan-Australia Workshop on Food Processing 1992, 78.

4. Bahram, S.; Rezaei, M.; Soltani, M.; Kamali, A.; Ojagh, S. M.; Abdollahi, M.; J. Food Process. Preserv. 2014, 38, 1251.

5. Bourtoom, T.; Int. Food Res. J. 2008, 15, 237.

6. Santacruz, S.; Rivadeneira, C.; Castro, M. Food Hydrocolloids 2015, 49, 94.

7. Krochta, J. M.; Proteins as raw materials for films and coatings: definitions, current status and opportunities. Boca Raton: CRC Press, 2002.

8. Cerqueira, M. A.; Bourbon, A. I.; Pinheiro, A. C.; Martins, J. T.; Souza, B. W. S.; Teixeira, J. A.; Vicente, A. A.; Trends Food Sci. Technol. 2011, 22,662 .

9. Antoniou, J.; Liu, F.; Majeed, H.; Zhong, F.; Food Hydrocolloids 2015, 44, 309.

10. Moura, M. R.; Aouada, F. A.; Avena-Bustillos, R. J.; McHugh, T. H.; Krochta, J. M.; Mattoso, L. H. C.; J. Food Eng. 2009, 92, 448.

11. Hosseini, S. F.; Rezaei, M.; Zandi, M.; Farahmandghavi, F.; Food Hydrocolloids 2015, 44, 172.

12. Cádiz-Gurrea, M.L.; Lozano-Sanchez, J.; Contreras-Gámez, M.; LegeaiMallet, L.; Fernández-Arroyo, S.; Segura-Carretero A.; J. Funct. Foods 2014, 10, 485 .

13. Calvo, P. C.; Rem nán-López, M. J; Vila-Jato, A.; J. Appl. Polym. Sci. 1997, 63, 125 .

14. Espitia, P. J. P.; Avena-Bustillos, R. J.; Du, W.; Teófilo, R. F.; Soares, N. F. F.; McHugh, T. H.; Food Packaging and Shelf Life 2014, 2, 38.

15. Martelli, M. R.; Barros, T.T.; De Moura, M. R.; Mattoso, L. C. H.; Assis, O. B. G.; J. Food Sci. 2013, 78, 98.

16. Lorevice, M. V.; De Moura, M. R.; Aouada, F. A.; Mattoso, L. H. C.; J. Nanosci. Nanotechnol. 2012, 11, 1 .

17. Azeredo, H. M. C.; Mattoso, L. C. H.; Wood, D.; Williams, T. G.; AvenaBustillos, R. J.; McHugh, T. H.; J. Food Sci. 2009, 74, 31.

18. ASTM Standard test method for water vapor transmission of materials, 1980. E96-80. In: Annual Book of American Standard Testing Methods. Philadelphia, USA, PA: ASTM.

19. McHugh, T. H.; Avena-Bustillos, R.; Krochta, R. J.; J. Food Sci. 1993 , 58,899 .

20. ASTM Standard test method for tensile properties of thin plastic sheeting, 1997. D882-97. In Annual Book of American Standard Testing Methods. Philadelphia, USA, PA: ASTM.

21. Lorevice, M. V.; De Moura, M. R.; Mattoso, L.H. C.; Quim. Nova 2014, $37,931$.

22. Chang, P.R; Jian, R.; Yu, J.; Ma, X.; Food Chem. 2010, 120, 736

23. Krochta J. M.; Baldwin, E. A.; Nisperos-Carriedo, M.; Edible coatings and films to improve food quality, $1^{\text {th }}$ ed., Boca Raton: CRC Press, 1994.

24. Gómez-Estaca, J.; Gómez-Guillén, M.C.; Fernández-Martín, F.; Montero, P.; Food Hydrocolloids 2011, 25, 1461.

25. Huq, T.; Salmieri, S.; Khan, A.; Khan, R. A.; Tien, C. L.; Riedl, B.; Fraschini, C.; Bouchard, J.; Uribe-Calderon, J.; Kamal, M. R.; Monique Lacroix, M.; Carbohydr. Polym. 2012, 90, 1757. 